\title{
Color Stabilization of Red Wines. A Chemical and Colloidal Approach
}

\author{
Cristina Alcalde-Eon, ${ }^{\dagger}$ Ignacio García-Estévez, ${ }^{\dagger}$ Victor Puente, ${ }^{\S}$ Julián C. Rivas-Gonzalo, ${ }^{\dagger}$ \\ and M. Teresa Escribano-Bailón* ${ }^{\dagger}$ \\ ${ }^{\dagger}$ Grupo de Investigación en Polifenoles, Unidad de Nutrición y Bromatología, Facultad de Farmacia, Universidad de Salamanca, \\ Campus Miguel de Unamuno, E 37007 Salamanca, Spain \\ ${ }^{\S}$ Laffort España, Polígono Txirrita Maleo 12, Rentería, Spain
}

ABSTRACT: The effects of cold treatment and time on CIELAB color parameters and on anthocyanin and anthocyanin-derived pigments composition have been evaluated as has been the effectiveness of either an enological tannin or a mannoprotein (M) on their stabilization. With respect to color, hue $\left(h_{a b}\right)$ was increased in the wines treated with both enological products. Furthermore, the color changes induced by cold treatment were lessened by the addition of these two enological products, although the protective effect was higher for the wines treated with $\mathrm{M}$. The pigment analysis revealed higher percentages of anthocyanin-derived pigments in tannin and M-treated samples (in both cold treated and not) in relation to control ones. The addition of the enological tannin may favor the synthesis of anthocyanin-derived pigments, which are chemically more stable than native anthocyanins, whereas $\mathrm{M}$ seems to stabilize anthocyanin-derived pigments from a colloidal point of view, avoiding their aggregation and further precipitation.

KEYWORDS: red wine, anthocyanins, anthocyanin-derived pigments, A-type vitisins, enological tannin, mannoproteins, colloidal stabilization

\section{INTRODUCTION}

Color is generally the first organoleptic property of a wine that is perceived by consumers and it is, therefore, responsible for the consumers' first opinion of a given wine. Furthermore, color may condition the perception of the aroma, taste, or mouthfeel properties of a wine. ${ }^{1,2}$ Anthocyanins are the main pigments responsible for wine color, and they are extracted from grape skins throughout maceration. During winemaking and aging they are involved in chemical reactions leading either to their degradation or to their transformation into derivative and/or polymeric pigments. Consequently, wine color changes during aging and different hues are associated with the different stages of wine life. In addition to this chemical transformation, the red wine coloring matter can undergo precipitation phenomena that may occur both in young and in aged wines. In young wines it is related to the colloidal state of this coloring matter and to the molecular size, and it depends on the wine's alcohol content and storage temperature. In aged wines it is more related to the polymerization reactions of tannins and anthocyanins. ${ }^{3}$ The initial rejection of a wine by consumers can be due not only to its poor color or the presence of precipitates in the bottle but also to unexpected hues in relation to its age. For these reasons, the physicochemical stabilization of the color of red wines is one of the main concerns of enologists.

In relation to chemical stabilization, it is well-known that anthocyanins participate in different reactions leading to derivative pigments that are more stable than anthocyanins, at least from a chemical point of view. Anthocyanins can react through their $\mathrm{C} 4$ position with other wine constituents such as pyruvic acid, acetaldehyde, vinylphenols, hydroxycinnamic acids, and vinylcatechins to originate different types of pyranoanthocyanins. ${ }^{4}$ These compounds are more resistant than the original anthocyanins to color loss through hydration or bisulfite bleaching. ${ }^{5-8}$ The reaction of anthocyanins with tannins mediated by acetaldehyde is also considered a mechanism to increase color chemical stability. ${ }^{7,9}$ Nevertheless, excessive polymerization can lead to precipitation. ${ }^{10}$ Flavanolanthocyanin direct condensation products, on the contrary, show resistance toward hydration similar to that of native anthocyanins. ${ }^{11}$ Noncovalent interactions such as copigmentation (between anthocyanins and copigments, such as hydroxycinnamic acids or catechins) or self-association (between anthocyanins) can also protect anthocyanins from degradation. ${ }^{12,13}$ Different reasons can lead winemakers to add enological tannins to the wine, ${ }^{14}$ among them, the claimed improvement of color and the increase of the stability of wine pigments. The beneficial effect on wine color was first empirically observed, and then the increase of the knowledge on tannin-anthocyanin interactions led to hypotheses on the effects of the additions of these enological tannins. Nevertheless, there are few publications evaluating the effects of these exogenous tannins on wine color and pigment composition. ${ }^{15-18}$ Enological tannins can supply compounds to the wine that can take part directly or indirectly in reactions with anthocyanins favoring the synthesis of derivative pigments or can provide compounds that participate in copigmentation interactions or that protect them from oxidation. ${ }^{15,18}$

With respect to the colloidal stabilization of wine, there is less information available. Cold has been traditionally used to

Special Issue: International Workshop on Anthocyanins (IWA2013)

Received: December 11, 2013

Revised: $\quad$ March 4, 2014

Accepted: March 5, 2014

Published: March 5, 2014 
stabilize wines. This technique causes the precipitation of tartrates and unstable colloidal substances and aims at avoiding further undesirable precipitations and wine turbidity. ${ }^{3}$ Nevertheless, cold can also precipitate coloring matter either by adsorption on the tartrate crystals or by the instability of colloidal coloring matter. The role of wine polysaccharides in preventing those phenomena has been proposed. The mannoproteins are considered to be protective colloids that can hinder tartrate crystallization, ${ }^{3}$ avoiding the growth of the crystals. Furthermore, they play an important part in protein haze stabilization. ${ }^{19}$ They are glycoproteins of the Saccharomyces cerevisiae cell wall that can be excreted to the wine during alcoholic fermentation or be released to the wine during yeast autolysis. ${ }^{20}$ Although the compositions of these two types of mannoproteins are quite similar, only the mannoproteins released from cell walls seem to exert the stabilizing effects. ${ }^{21}$ Recently, it has been reported that mannoproteins can also influence tannin aggregation by adsorption of the mannoproteins on the tannin molecule, preventing the growth of the tannin particles. ${ }^{22,23}$ Nevertheless, Poncet-Legrand and coworkers ${ }^{24}$ showed that the tannin-stabilizing effect depends on the molecular weight of the mannoprotein and also on other factors such as ethanol content or ionic strength. The results of that study confirmed that mannoproteins seem to act as steric stabilizers. Taking into account that mannoproteins were able to stabilize tannins, it was hypothesized that they might also act as stabilizers of the colloidal coloring matter. In fact, different mannoprotein-rich commercial preparations are now available, ${ }^{25}$ and among the benefits claimed by manufacturers is the increase of color stabilization. However, studies on the effects of mannoproteins on wine color and pigment composition are scarce. Escot and co-workers ${ }^{26}$ reported that the presence of mannoproteins released by yeast to the wine during alcoholic fermentation improved color stability. Guadalupe and coworkers, on the contrary, reported that the mannoproteins released by mannoprotein-overproducing yeasts affected neither wine color nor monomeric anthocyanin content, ${ }^{27}$ whereas the addition of commercial mannoproteins during the prefermentation stage even caused a loss of stable wine color. $^{27,28}$ These differences in the behavior of mannoproteins might be related to differences in their composition. Fernández and co-workers ${ }^{29}$ observed greater color intensity and a slight tendency to red tones when the wine was treated with lysated lees obtained by acidification and enzymatic treatment instead of those obtained only by acidification. Nevertheless, none of these works study the influence that mannoproteins can exert on the colloidal stability of anthocyanin-derived pigments, the influence of which on wine color cannot be neglected in aged wines. Furthermore, the usefulness of these products on preventing color loss by cold treatment has to be studied.

The objective of the present study was to assess the chemical and colloidal stabilization of wine color and pigment composition as a consequence of the addition during alcoholic fermentation of either an enological tannin containing hydrolyzable and condensed tannins or a mannoprotein obtained from yeast by enzymatic treatment. The effect of these two enological products on preventing the loss of coloring matter has also been studied after wines had been submitted to cold stabilization treatment. Samples were analyzed after malolactic fermentation and 10 weeks later to verify if the effects were maintained over time. CIELAB parameters were used to evaluate color modifications, whereas changes in pigment composition were assessed by HPLC-

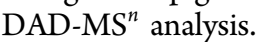

\section{MATERIALS AND METHODS}

Samples. Three different wines (100 L of each) were made from Vitis vinifera L. cv. Tempranillo grapes. The first wine served as control (C), whereas the second and third wines were treated with an enological tannin and with a mannoprotein (product $\mathrm{M}$ ), respectively (wines $\mathrm{T}$ and $\mathrm{M}$ ). All of the wines were made in duplicate. Following the manufacturer's advice these enological products (100\% soluble in wine) were added in equal amounts during alcoholic fermentation at densities 1100, 1060, and $1020 \mathrm{~g} / \mathrm{L}$, reaching a final concentration of $35 \mathrm{~g} / \mathrm{hL}$ (dose recommended by manufacturer). Further details of these enological products are given below. Maceration-alcoholic fermentation lasted 12 days. Then, the wines were inoculated with Oenococcus oeni and malolactic fermentation (MLF) took place, lasting 20 days. After MLF, two aliquots of $10 \mathrm{~L}$ from each wine were separated from the rest of the sample. One aliquot was cold-treated, whereas the other was not subjected to this treatment. Cold treatment consisted in cooling samples at $4{ }^{\circ} \mathrm{C}$ during $48 \mathrm{~h}$ followed by centrifugation during $10 \mathrm{~min}$ at $3000 \mathrm{rpm}$. Both aliquots were filtered $(2 \mu \mathrm{m})$ and then bottled (bottles of $750 \mathrm{~mL}$ ). Furthermore, the precipitate was recovered and dissolved in model wine solution $(5 \mathrm{~g} / \mathrm{L}$ of tartaric acid in $12 \%$ aqueous ethanol adjusted to $\mathrm{pH} 3.6$ ). The CIELAB color parameters and the pigment composition of the wines not subjected to cold treatment (C1, T1, and M1) and of those coldtreated $\left(\mathrm{C} 1^{*}, \mathrm{~T}^{*}\right.$, and $\left.\mathrm{M} 1^{*}\right)$ as well as of the redissolved precipitates (C1p, T1p, and Mlp) were then determined. Another bottle of each fraction (subjected and not subjected to cold) was kept in the dark and at $15{ }^{\circ} \mathrm{C}$ and analyzed 10 weeks after the first analysis (wines $\mathrm{C} 2, \mathrm{~T} 2$, $\mathrm{M} 2, \mathrm{C} 2 *, \mathrm{~T} 2 *$, and $\mathrm{M} 2 *$ ).

Enological Tannin. The enological tannin (Tanin VR Color) was supplied by Laffort España (Rentería, Spain) and consisted of an extract from natural sources mainly constituted by catechins and proanthocyanidins $(58.8 \%)$, oak ellagitannins $(11.2 \%)$, and hydroxybenzoic acids (7.5\%). The composition of the enological tannin was determined in our laboratory by means of HPLC-DAD-MS employing the conditions described by Ferrer-Gallego and co-workers ${ }^{30}$ for the analysis of catechins and proanthocyanidins.

Yeast Mannoproteins (Product M). In a preliminary study two commercial mannoproteins and four different mannoproteins obtained by Laffort from $S$. cerevisiae by either enzymatic or thermal treatments were tested to evaluate their potential protective effect on the colloidal unstable coloring matter of the wines. Among all of the tested mannoproteins only one (product $\mathrm{M}$, obtained by enzymatic treatment) showed a statistically significant protective effect, and for this reason it was selected for the present study. Other tested mannoproteins, on the contrary, even provoked additional precipitation, which is in accordance with the results of previous studies that did not find a protective effect of mannoproteins on coloring matter. ${ }^{27,28}$ Gel permeation chromatography revealed that all of the tested mannoproteins contained three main peaks that were present in different percentages. In relation to the other mannoproteins, product $\mathrm{M}$ showed a higher percentage $(50 \%)$ of the heaviest peak $(70 \mathrm{kDa})$.

Colorimetric Measurements. Because wine color is dependent on $\mathrm{pH}$, it was standardized in all of the samples to 3.6 with $0.1 \mathrm{~N} \mathrm{HCl}$ (Panreac, Castellar del Vallès, Spain) prior to the spectrophotometric measurements. Absorption spectra $(190-1100 \mathrm{~nm})$ were recorded in a Hewlett-Packard UV-vis HP 8453 (Agilent Technologies, Waldbronn, Germany) spectrophotometer in $2 \mathrm{~mm}$ path length quartz cells. The analysis of color was made only from the visible spectra (380-770 $\mathrm{nm})$ data, using the CIE 1964 standard observer $\left(10^{\circ}\right.$ visual field $)$ and the CIE standard illuminant D65 as references. CIELAB color parameters $\left(L^{*}, a^{*}, b^{*}, C_{a b}{ }^{*}\right.$, and $\left.h_{a b}\right)$ were calculated using the software CromaLab. ${ }^{31}$ Color differences between different wine samples were determined by means of the CIELAB color difference formula:

$$
\Delta E_{a b} *=\left(\left(\Delta L^{*}\right)^{2}+\left(\Delta a^{*}\right)^{2}+\left(\Delta b^{*}\right)^{2}\right)^{1 / 2}
$$


Table 1. CIELAB Parameters (Mean Values, $n=2$ ) of the Different Samples (C, Control; T, Tannin-Treated; M, Mannoprotein-Treated) at the Different Sampling Points (1, after Malolactic Fermentation; 2, 10 Weeks after Malolactic Fermentation) and in Non-Cold-Treated and Cold-Treated (*) Samples ${ }^{a}$

\begin{tabular}{|c|c|c|c|c|c|c|}
\hline \multicolumn{7}{|c|}{ Sampling Point 1} \\
\hline & $L^{*}$ & $a^{*}$ & & \multicolumn{2}{|r|}{$C_{a b} *$} & $h_{a b}$ \\
\hline $\mathrm{C} 1$ & 59.04 a $\alpha, \beta$ & 42.89 a $\alpha, \beta$ & & \multicolumn{2}{|r|}{42.89 a $\alpha$} & 0.44 a $\alpha, \beta$ \\
\hline $\mathrm{T} 1$ & 51.38 a $\alpha, \beta$ & 48.53 a $\alpha, \beta, \chi$ & & \multicolumn{2}{|r|}{48.62 a $\alpha, \beta$} & $3.44 \mathrm{~b} \beta$ \\
\hline M1 & 48.91 a $\alpha$ & 50.72 a $\chi$ & & \multicolumn{2}{|r|}{50.84 a $\beta$} & $3.87 \mathrm{~b} \beta$ \\
\hline $\mathrm{C} 1 *$ & 73.12 b 2 & 24.86 b 1 & & \multicolumn{2}{|r|}{25.12 b 1} & 8.26 c 2 \\
\hline $\mathrm{T} 1 *$ & 54.63 a 1 & 46.71 a 2 & & \multicolumn{2}{|r|}{46.76 a 2} & $2.58 \mathrm{a}, \mathrm{b} 1,2$ \\
\hline $\mathrm{M} 1^{*}$ & 51.67 a 1 & 48.42 a 2 & & \multicolumn{2}{|r|}{48.52 a 2} & 3.55 b 1,2 \\
\hline \multicolumn{7}{|c|}{ Sampling Point 2} \\
\hline & $L^{*}$ & $a^{*}$ & & \multicolumn{2}{|r|}{$C_{a b} *$} & $h_{a b}$ \\
\hline $\mathrm{C} 2$ & $59.70 \beta$ & $42.36 \alpha$ & & \multicolumn{2}{|r|}{$42.39 \alpha$} & $-1.75 \alpha$ \\
\hline $\mathrm{T} 2$ & $52.10 \alpha, \beta$ & $47.63 \alpha, \beta, \chi$ & & \multicolumn{2}{|r|}{$47.65 \alpha, \beta$} & $0.99 \alpha, \beta$ \\
\hline $\mathrm{M} 2$ & $49.54 \alpha, \beta$ & $49.88 \beta, \chi$ & & \multicolumn{2}{|r|}{$49.89 \alpha, \beta$} & $1.32 \alpha, \beta$ \\
\hline $\mathrm{C} 2 *$ & 73.052 & 25.731 & & \multicolumn{2}{|r|}{25.921} & $6.931,2$ \\
\hline $\mathrm{T} 2 *$ & 54.711 & 46.192 & & \multicolumn{2}{|r|}{46.192} & 0.151 \\
\hline $\mathrm{M} 2 *$ & 49.981 & 46.192 & & \multicolumn{2}{|r|}{46.312} & $3.301,2$ \\
\hline \multicolumn{7}{|c|}{ Differences Due to the Addition of Enological Products } \\
\hline & $\Delta L^{*}$ & $\Delta a^{*}$ & $\Delta b^{*}$ & $\Delta \mathrm{C}_{a b} *$ & $\Delta h_{a b}$ & $\Delta E_{a b} *$ \\
\hline $\mathrm{T} 1-\mathrm{C} 1$ & -7.66 & 5.64 & 2.59 & 5.73 & 3.00 & 9.86 \\
\hline $\mathrm{M} 1-\mathrm{C} 1$ & -10.13 & 7.84 & 3.09 & 7.95 & 3.44 & 13.17 \\
\hline \multicolumn{7}{|c|}{ Differences Due to Cold Treatment } \\
\hline & $\Delta L^{*}$ & $\Delta a^{*}$ & $\Delta b^{*}$ & $\Delta C_{a b} *$ & $\Delta h_{a b}$ & $\Delta E_{a b} *$ \\
\hline $\mathrm{C} 1 *-\mathrm{C} 1$ & $14.08 \mathrm{~b}$ & $-18.03 \mathrm{~b}$ & $3.27 \mathrm{a}$ & $-17.77 \mathrm{~b}$ & $7.82 \mathrm{~b}$ & $23.11 \mathrm{~b}$ \\
\hline $\mathrm{T} 1 *-\mathrm{T} 1$ & $3.25 \mathrm{a}$ & $-1.83 \mathrm{a}$ & -0.81 a & -1.87 a & $-0.86 \mathrm{a}$ & $3.82 \mathrm{a}$ \\
\hline $\mathrm{M} 1 *-\mathrm{M} 1$ & $2.77 \mathrm{a}$ & $-2.30 \mathrm{a}$ & $-0.43 \mathrm{a}$ & $-2.32 \mathrm{a}$ & $-0.32 \mathrm{a}$ & $3.62 \mathrm{a}$ \\
\hline \multicolumn{7}{|c|}{ Differences Due to Time } \\
\hline & $\Delta L^{*}$ & $\Delta a^{*}$ & $\Delta b^{*}$ & $\Delta C_{a b} *$ & $\Delta h_{a b}$ & $\Delta E_{a b} *$ \\
\hline $\mathrm{C} 2-\mathrm{C} 1$ & 0.66 & -0.53 & -1.64 & -0.51 & -2.19 & 1.85 \\
\hline $\mathrm{T} 2-\mathrm{T} 1$ & 0.72 & -0.90 & -2.09 & -0.98 & -2.45 & 2.39 \\
\hline $\mathrm{M} 2-\mathrm{M} 1$ & 0.63 & -0.85 & -2.28 & -0.95 & -2.55 & 2.51 \\
\hline $\mathrm{C} 2 *-\mathrm{C} 1^{*}$ & -0.07 & 0.87 & -0.51 & 0.80 & -1.33 & 1.01 \\
\hline $\mathrm{T} 2 *-\mathrm{T} 1 *$ & 0.08 & -0.52 & -2.00 & -0.57 & -2.43 & 2.07 \\
\hline $\mathrm{M} 2 *-\mathrm{M} 1 *$ & -1.70 & -2.24 & -0.35 & -2.21 & -0.25 & 2.83 \\
\hline $\mathrm{T} 2-\mathrm{C} 1$ & -6.93 & 4.74 & 0.50 & 4.75 & 0.55 & 8.42 \\
\hline $\mathrm{M} 2-\mathrm{C} 1$ & -9.50 & 6.98 & 0.81 & 7.00 & 0.88 & 11.82 \\
\hline
\end{tabular}

${ }^{a}$ Differences due to the addition of the enological products, to cold treatment and time are also shown. Letters a-c following entries show the significance of the differences among the samples of the first sampling point ( $\mathrm{C} 1, \mathrm{~T} 1, \mathrm{M} 1, \mathrm{C} 1 *, \mathrm{~T} 1^{*}$, and $\left.\mathrm{M} 1^{*}\right)$. Letters $\alpha, \beta$, and $\chi$ following entries show the significance of the differences due to time in non-cold-treated samples (C1, T1, M1, C2, T2, and M2). Numbers $1-3$ following entries show the significance of the differences due to time in cold-treated samples $\left(\mathrm{C} 1^{*}, \mathrm{~T} 1^{*}, \mathrm{M} 1^{*}, \mathrm{C} 2^{*}, \mathrm{~T} 2^{*}\right.$, and $\left.\mathrm{M} 2^{*}\right)$. $p<0.05$ in all cases.

HPLC-DAD-ESI/MS ${ }^{n}$ Analyses. The anthocyanins and derivative pigments were analyzed by HPLC-DAD-MS ${ }^{n}$ in all of the wine samples (cold-treated and non-cold-treated) as well as in the precipitates of the cold-treated samples. Wine samples were diluted $(1 / 5)$ with acidified water $(\mathrm{pH} 1.3, \mathrm{HCl})$ and filtered through a 0.45 $\mu \mathrm{m}$ Millex syringe-driven filter unit (Millipore Corp., Bedford, MA, USA) before HPLC-DAD-MS analysis. The precipitates that had been redissolved in model wine solution were also acidified $(0.25 \mathrm{~mL}$ acidified water/mL sample) and filtered prior to the HPLC-DAD-MS analysis. Analyses were performed in a Hewlett-Packard 1100 series liquid chromatograph (Agilent Technologies, Waldbronn, Germany). An AQUA C18 reversed-phase, $5 \mu \mathrm{m}, 150 \mathrm{~mm} \times 4.6 \mathrm{~mm}$ column (Phenomenex, Torrance, CA, USA) thermostated at $35^{\circ} \mathrm{C}$ was used. The HPLC-DAD conditions have been previously employed with satisfactory results in our laboratory in the analysis of wine samples. ${ }^{32}$ Detection was carried out at $520 \mathrm{~nm}$ as the preferred wavelength. Spectra were recorded from 220 to $600 \mathrm{~nm}$. The mass spectrometer was connected to the HPLC system via the DAD cell outlet. MS detection was performed in an API 3200 Qtrap (Applied Biosystems, Darmstadt, Germany) equipped with an ESI source and a triple- quadrupole ion trap mass analyzer that was controlled by Analyst 5.1 software. MS analysis was carried out in positive mode $\left(\mathrm{ESI}^{+}\right)$. Zero grade air served as nebulizer gas (GS1) and turbo gas (GS2) for solvent drying. Nitrogen served as curtain (CUR) and collision gas $(\mathrm{CAD})$. Settings used were optimized by direct infusion of a malvidin 3-O-glucoside solution: declustering potential (DP), $41 \mathrm{~V}$; entrance potential (EP), $7.5 \mathrm{~V}$; ion spray voltage (IS), $5000 \mathrm{~V}$; GS1, $40 \mathrm{psi}$; GS2, 50 psi $\left(600{ }^{\circ} \mathrm{C}\right)$; CUR, 20 psi; and CAD, set as "high". Both quadrupoles were set at unit resolution. Mass method consisted of three mass experiments: full mass analysis (EMS mode, collision energy (CE) $10 \mathrm{~V}$ ), $\mathrm{MS}^{2}$ analysis (EPI mode, CE $25 \mathrm{~V}$ ), and $\mathrm{MS}^{3}$ analysis (CE $30 \mathrm{~V}$, excitation energy (AF2) $50 \mathrm{~V}$ ). Spectra were recorded between $\mathrm{m} / z 150$ and 1300 .

Compounds were identified from the data supplied by the HPLC$\mathrm{DAD}-\mathrm{MS}^{n}$ analyses of the samples (retention time, UV-vis spectra, $\mathrm{m} / \mathrm{z}$ ratio, and fragmentation patterns) and by comparison to the data previously obtained in our laboratory for wine samples analyzed in the same conditions. ${ }^{32}$ Thirty-one anthocyanins and derivative pigments were determined: 5 anthocyanin 3-O-glucosides, 5 anthocyanin 3-Oacetylglucosides, 8 anthocyanin 3-O-coumaroylglucosides (5 trans 
isomers and 3 cis isomers), 2 anthocyanin 3-O-caffeoylglucosides, 7 flavanol-anthocyanin direct condensation products (F- $\mathrm{A}^{+}$dimers), 2 A-type vitisins, a B-type vitisin of malvidin 3-O-glucoside, and the vinylphenol-malvidin 3-O-glucoside pyranoanthocyanin. All of these compounds were considered for the quantitative analysis. As it usually happens in the analysis of wine samples by HPLC, an elevation of the baseline was observed at the end of the chromatogram corresponding to difficult resolution pigments, such as dimeric anthocyanins. ${ }^{33}$ Although it is difficult to know the exact composition of these unresolved peaks, it is important to know their percentage over the total coloring matter because they show absorbance at $520 \mathrm{~nm}$ and can, therefore, contribute to the final color of the wine. Their contribution was assessed as the absorbance of the "hump" formed above the theoretical baseline. Because the final color of a wine depends both on the total pigment content and on the proportions of the different types of pigments, the percentage of each compound over the total area was calculated.

Total pigment content of each sample was also calculated and expressed as malvidin 3-O-glucoside (Extrasynthèse, Genay, France).

Statistical Analysis. The CIELAB parameters, the percentages of the different pigments, and their modifications with cold treatment and with time were analyzed by means of one-way analysis of variance (ANOVA) and Tukey's honestly significant difference test to assess the significance of the differences observed among samples $(p<0.05)$. An unsupervised pattern recognition method, principal components analysis (PCA), was used for data analysis. PCA was applied from the correlation matrix of the original variables (mean percentages of the 31 identified pigments and that of the difficult resolution pigments).

Student's $t$ test was employed to evaluate the statistical significance between pairs of samples (95\% confidence levels). The IBM-SPSS Statistics 21 for Windows software package (IBM, Armonk, NY, USA) was used to carry out the statistical analysis.

\section{RESULTS AND DISCUSSION}

Chromatic Analysis. It is relevant to first analyze the color modifications that are a direct consequence of the addition of these two enological products to the wine. It has been observed that the addition of either the enological tannin or product $M$ causes a decrease in lightness $\left(L^{*}\right)$ and an increase in $a^{*}$ and $b^{*}$ coordinates and consequently an increase in chroma $\left(C_{a b}{ }^{*}\right)$ and in hue $\left(h_{a b}\right)$ in relation to those observed in nontreated samples (Table 1$)$. Nevertheless, only the changes in $b^{*}$ coordinate and in hue were statistically significant. Although the changes were more noticeable in the samples to which product $M$ was added than in those treated with enological tannin, the differences among tannin and M-treated samples were not statistically significant (Table 1). Color differences between control and tannin- or M-treated wines were assessed by $\Delta E_{a b} *$. In both cases $\Delta E_{a b} *$ was $>3$, which means that the color modifications induced by the treatments are visible to the human eye. ${ }^{34}$ Previous studies on mannoproteins and their influence on wine color $^{27,28}$ reported that in the tested conditions the mannoproteins did not modify wine color in relation to control samples, and they even observed the precipitation of stable color when the mannoprotein was added to the wine as an extract but not when mannoprotein-overproducing yeast strains were used. This was not observed in the present study. Differences might be related to the type of mannoprotein employed. As previously indicated, the molecular weight, the source from which they are obtained, or the methodology employed to obtain them ${ }^{21,24,29}$ can modify the effect of the mannoproteins. Nevertheless, as in our study, Guadalupe and co-workers ${ }^{27}$ observed an increase in the $b^{*}$ coordinate in wines fermented with a mannoprotein-overproducing yeast strain either in the absence or in the presence of a commercial mannoprotein.
Thus, from these first results it can be concluded that the addition of the enological tannin or product $M$ to the wines modifies the values of the CIELAB color parameters observed in control wines.

Modification of the CIELAB Parameters after Cold Treatment. In relation to lightness, it was observed that the samples that underwent cold stabilization increased their $L^{*}$ value in relation to those not subjected to cold treatment (see "Sampling Point 1" and "Differences Due to Cold Treatment" in Table 1). This fact can be related to the precipitation of compounds after cold treatment, either directly due to their own instability or indirectly by adsorption to compounds such as tartrates, which easily precipitate with cold. Differences have been observed among the different samples. In control samples $L^{*}$ increased ca. 14 units after cold treatment. However, in the cases of either tannin- or M-treated wines the values of $L^{*}$ determined in the samples not subjected to cold treatment (T1 and $\mathrm{M} 1)$ and in those subjected to cold treatment ( $1^{*}$ and M1*, respectively) were not statistically different. Furthermore, $\Delta L^{*}$ due to cold treatment was not statistically different in tannin- or M-treated wines. This is indicative of a stabilizing effect of both types of compounds against cold precipitation.

As can be observed in Table 1 (see "Sampling Point 1" and "Differences Due to Cold Treatment"), cold treatment caused a significant increase in the $b^{*}$ coordinate only in the case of control wines. On the contrary, the $a^{*}$ coordinate decreased in all samples, although it was only statistically significant in the case of control wines. This might be pointing to a color stabilization effect toward cold treatment caused by the addition of these two enological products. From these two parameters $\left(a^{*}\right.$ and $\left.b^{*}\right)$, chroma $\left(C_{a b}{ }^{*}\right)$ and hue $\left(h_{a b}\right)$ parameters can be calculated. Although chroma decreased in all of the samples after cold treatment, only the changes observed in control wines were significant. Thus, wines treated with the enological tannin or with product $M$ were able to better maintain their own quantity of color after cold treatment. With respect to hue, after cold treatment, it significantly increased in control wines, shifting color toward more orange hues. On the contrary, hue remained quite stable after cold stabilization in tannin- or M-treated wines (Table 1).

From these results it seems that the addition of these two products to the wine allows a stabilization of the coloring matter against cold treatment. In fact, whereas cold treatment caused a color difference $\left(\Delta E_{a b}{ }^{*}\right)$ of 23 units in control samples, in treated samples it hardly exceeded the human eye threshold of 3 units. The main initial drawback might be the slight shift of the wine color toward red-orange hues observed after the addition of these two enological products. However, after cold treatment, the color in the wines treated with these two products ( $1_{1}^{*}$ and $\mathrm{M} 1^{*}$ ) is redder than that of coldtreated control wines $\left(\mathrm{Cl}^{*}\right)$ and darker and with higher chroma than that of control wines even before cold treatment (C1).

Modification of the CIELAB Parameters over Time. The color parameters of these samples were studied 10 weeks after cold treatment to determine if the effect of the addition of either the enological tannin or product $M$ is maintained over time.

In all samples, the modification in lightness $\left(\Delta L^{*}\right)$ caused by time (between sampling points 2 and 1 ) is much lower than that caused by cold treatment (Table 1 ). This might indicate that there has not been an important quantitative change in pigment composition such as additional pigment precipitation. 


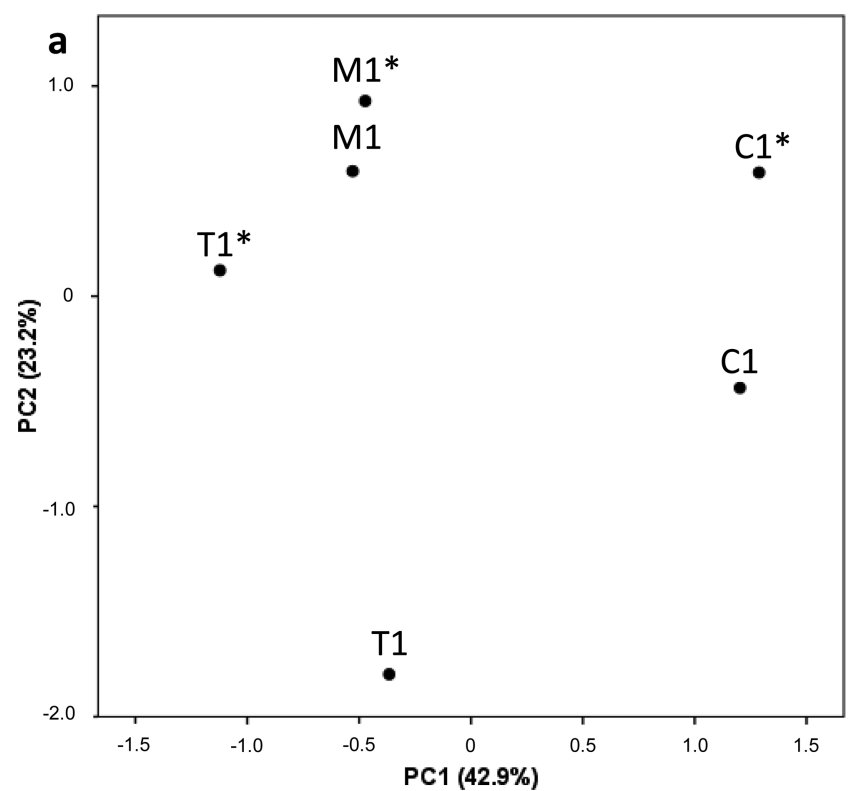

b

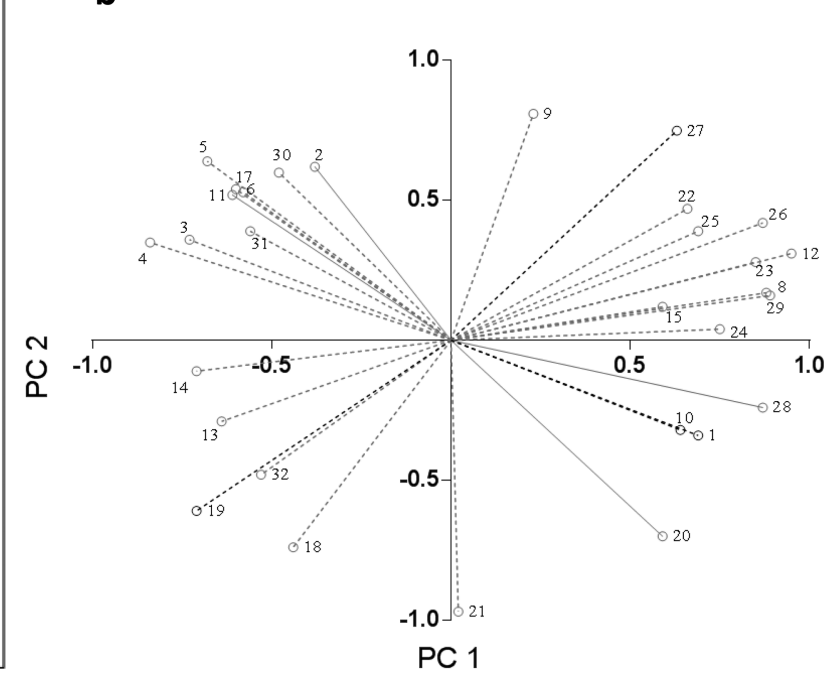

Figure 1. (a) Projection of the wine samples on the plane defined by the first and second principal components (PC2 vs PC1). These samples correspond to all wines (control, tannin- and M-treated wines) in the first sampling point either subjected to cold treatment (samples $\mathrm{C} 1^{*}, \mathrm{~T} 1 *$, and $\mathrm{M1}^{*}$ ) or not (samples C1, T1, and M1). (b) Loading plot of the PCA. The identities of the original variables are indicated in Table 2.

Furthermore, the modifications in $L^{*}\left(\Delta L^{*}\right)$ produced by time were not significantly different among the different kinds of samples (control, tannin- or M-treated samples).

With respect to $a^{*}$ and $b^{*}$ parameters and their modification over time $\left(\Delta a^{*}\right.$ and $\Delta b^{*}$ between sampling points 2 and 1 , Table 1, "Differences Due to Time"), it can be seen that, in most cases, time produced a decrease in both parameters. In addition, no significant differences can be observed in the values of $\Delta a^{*}$ and $\Delta b^{*}$ among samples, which indicates that time affects $a^{*}$ and $b^{*}$ in a similar way in all of the samples, independently of the initial treatment. Because chroma and hue depend on $a^{*}$ and $b^{*}$ parameters, they also decreased over time in most of the samples (see $\Delta C_{a b} *$ and $\Delta h_{a b}$ in Table 1). As in the case of $\Delta a^{*}$ and $\Delta b^{*}$, no significant differences were observed in the evolution of chroma and hue $\left(\Delta C_{a b} *\right.$ and $\left.\Delta h_{a b}\right)$ over time among the different treatments either in the samples not subjected to cold treatment or in the samples cold-treated (compare $\mathrm{C} 2-\mathrm{C} 1, \mathrm{~T} 2-\mathrm{T} 1, \mathrm{M} 2-\mathrm{M} 1, \mathrm{C} 2 *-\mathrm{C} 1 *, \mathrm{~T} 2 *-\mathrm{T} 1 *$, and $\mathrm{M} 2 *-\mathrm{M} 2$ ). It has to kept in mind that, on the contrary, cold treatment did affect differently the samples treated either with the enological tannin or with product $M$, observing significant differences in the values of $\Delta L^{*}, \Delta C_{a b}{ }^{*}$, and $\Delta h_{a b}$ between control samples and the samples treated with any of these enological products. As indicated in the previous section, their addition has been proven to produce a stabilization of the initial color of the samples against cold treatment in relation to the samples to which these products were not added (compare $\mathrm{C} 1{ }^{*}-\mathrm{C} 1$ to $\mathrm{T} 1{ }^{*}-\mathrm{T} 1$ and $\mathrm{M} 1-\mathrm{M} 1 *$ in Table 1$)$. This might indicate that the addition of these two types of enological products might be useful to prevent color loss due to cold but not to prevent changes in color due to age. Cold treatment mainly affects pigment composition by precipitation (reflected in the changes in $L^{*}$ and $C_{a b}$, above all), whereas pigment evolution over time involves chemical modifications of the pigments initially present (reflected in the changes in $h_{a b}$ ), which can be accompanied or not by precipitation. Nevertheless, the time range between sampling points 1 and 2 is too low (10 weeks) to draw conclusions about the possible long- term effect in pigment composition. In fact, slight differences in the behavior of the color parameters over time have been observed among the different types of cold-treated samples. Although not statistically significant, they might be pointing out differences in the mechanisms of both types of products. Furthermore, although the magnitude of the modifications over time in chroma and hue $\left(\Delta C_{a b}{ }^{*}\right.$ and $\left.\Delta h_{a b}\right)$ has been the same in all types of samples, the final colors of the tannin- or Mtreated samples not subjected to cold after 10 weeks show a hue similar to that of control wine before cold treatment at point 1 (compare $\mathrm{T} 2-\mathrm{C} 1$ and $\mathrm{M} 2-\mathrm{C} 1$, Table 1 ). This means that although these products have not been able to avoid the decrease in hue observed from point 1 to point 2 , the initial increase caused in this parameter by their addition has made up for this decrease. In other words, they have also "stabilized" the hue of the nontreated wine. Furthermore, treated wines (T2 and M2) were darker and possessed higher chroma than control wine at the first sampling point (C1).

Pigment Analysis. Because the addition of the enological tannin or product $M$ to the wine modified the initial color of the samples, it seems interesting to first analyze the modification induced in the pigment composition by these additions (compare $\mathrm{C} 1, \mathrm{~T} 1$, and $\mathrm{M} 1$ ). In relation to total pigment content, the samples to which the enological tannin was added (T1) showed the highest pigment content (630.3 $\mathrm{mg} / \mathrm{L})$ followed by those treated with product M (M1, 582.6 $\mathrm{mg} / \mathrm{L})$. Control samples (C1) showed the lowest total content $(541.3 \mathrm{mg} / \mathrm{L})$. This lower pigment content explains the higher $L^{*}$ value of control samples in relation to treated samples. The higher total pigment content observed in T1 samples might be related to a higher extraction of native grape pigments favored by the addition of the enological tannin as previously observed in our laboratory. ${ }^{18} \mathrm{~T} 1$ samples also showed the highest contents for each group of pigments in relation to the other types of samples. For this reason, the differences among types of wines were lower when the percentages of the different groups of pigments were considered. To evaluate the relevance of the different wine pigments on the differences observed 
Table 2. Individual Percentages of Pigments in Samples before Cold Treatment (C1, T1, and M1) and in Precipitates Obtained after Cold Treatment (C1p, T1p, and M1p) (Mean Values, $n=2)$

\begin{tabular}{|c|c|c|c|c|c|c|c|}
\hline \multirow[b]{2}{*}{ peak/variable } & \multirow[b]{2}{*}{ compound $^{b}$} & \multicolumn{6}{|c|}{ samples $^{a}$} \\
\hline & & $\mathrm{C} 1$ & $\mathrm{~T} 1$ & M1 & $\mathrm{C} 1 \mathrm{p}$ & $\mathrm{T} 1 \mathrm{p}$ & M1p \\
\hline 1 & F-A ${ }^{+}$GC-Dp-3-glc & $0.12 \mathrm{a}$ & $0.11 \mathrm{a}$ & $0.11 \mathrm{a}$ & nd & nd & nd \\
\hline 2 & F-A ${ }^{+}$GC-Pt-3-glc & $0.22 \mathrm{a}$ & $0.21 \mathrm{a}$ & $0.22 \mathrm{a}$ & nd & nd & nd \\
\hline 3 & F-A ${ }^{+}$GC-Mv-3-glc & $0.50 \mathrm{a}$ & $0.52 \mathrm{a}$ & $0.52 \mathrm{a}$ & $0.41 \mathrm{a}$ & $0.50 \mathrm{a}$ & $0.40 \mathrm{a}$ \\
\hline 4 & F-A ${ }^{+}$C-Cy-3-glc & $0.20 \mathrm{a}$ & $0.21 \mathrm{a}$ & $0.22 \mathrm{a}$ & nd & nd & nd \\
\hline 5 & F-A ${ }^{+} \mathrm{C}-\mathrm{Pt}-3-\mathrm{glc}$ & $0.30 \mathrm{a}$ & $0.34 \mathrm{a}$ & $0.40 \mathrm{a}$ & nd & nd & nd \\
\hline 6 & F-A ${ }^{+}$C-Pn-3-glc & $0.42 \mathrm{a}$ & $0.43 \mathrm{a}$ & $0.43 \mathrm{a}$ & $0.28 \mathrm{a}$ & $0.38 \mathrm{a}$ & $0.30 \mathrm{a}$ \\
\hline 7 & $\mathrm{~F}-\mathrm{A}^{+} \mathrm{C}-\mathrm{Mv}-3-\mathrm{glc}$ & $0.57 \mathrm{a}$ & $0.59 \mathrm{a}$ & $0.59 \mathrm{a}$ & $0.47 \mathrm{a}$ & $0.56 \mathrm{a}$ & $0.45 \mathrm{a}$ \\
\hline 8 & Dp-3-glc & $10.09 \mathrm{c}$ & $9.61 \mathrm{c}$ & $9.63 \mathrm{c}$ & $8.74 \mathrm{a}, \mathrm{b}$ & $8.15 \mathrm{a}$ & $9.34 \mathrm{~b}, \mathrm{c}$ \\
\hline 9 & Cy-3-glc & $1.22 \mathrm{c}$ & $1.18 \mathrm{~b}, \mathrm{c}$ & $1.28 \mathrm{c}$ & $0.89 \mathrm{a}$ & $1.08 \mathrm{a}, \mathrm{b}, \mathrm{c}$ & $1.00 \mathrm{a}, \mathrm{b}$ \\
\hline 10 & Pt-3-glc & $10.99 \mathrm{~b}$ & $11.01 \mathrm{~b}$ & $10.83 \mathrm{~b}$ & $9.30 \mathrm{a}$ & $9.07 \mathrm{a}$ & $10.37 \mathrm{~b}$ \\
\hline 11 & Vit A Pt-3-glc & $0.30 \mathrm{a}$ & $0.27 \mathrm{a}$ & $0.34 \mathrm{a}, \mathrm{b}$ & $0.54 \mathrm{c}$ & $0.46 \mathrm{~b}, \mathrm{c}$ & $0.45 \mathrm{~b}, \mathrm{c}$ \\
\hline 12 & Pn-3-glc & $3.37 \mathrm{a}$ & $3.08 \mathrm{a}$ & $3.18 \mathrm{a}$ & $3.30 \mathrm{a}$ & $3.05 \mathrm{a}$ & $3.30 \mathrm{a}$ \\
\hline 13 & Mv-3-glc & $44.48 \mathrm{a}$ & $45.33 \mathrm{a}$ & $44.83 \mathrm{a}$ & $40.06 \mathrm{a}$ & $38.40 \mathrm{a}$ & $45.60 \mathrm{a}$ \\
\hline 14 & Vit A Mv-3-glc & $0.53 \mathrm{a}$ & $0.55 \mathrm{a}$ & $0.59 \mathrm{a}$ & $1.44 \mathrm{c}$ & $1.13 \mathrm{~b}, \mathrm{c}$ & $0.96 \mathrm{a}, \mathrm{b}$ \\
\hline 15 & Dp-3-acetylglc & $0.46 \mathrm{a}$ & $0.46 \mathrm{a}$ & $0.44 \mathrm{a}$ & $0.41 \mathrm{a}$ & $0.42 \mathrm{a}$ & $0.41 \mathrm{a}$ \\
\hline 16 & Vit B Mv-3-glc & $0.08 \mathrm{a}$ & $0.10 \mathrm{a}$ & $0.08 \mathrm{a}$ & $0.15 \mathrm{a}$ & $0.15 \mathrm{a}$ & $0.15 \mathrm{a}$ \\
\hline 17 & Cy-3-acetylglc & $0.21 \mathrm{a}$ & $0.20 \mathrm{a}$ & $0.21 \mathrm{a}$ & $0.18 \mathrm{a}$ & $0.24 \mathrm{a}$ & $0.20 \mathrm{a}$ \\
\hline 18 & Pt-3-acetylglc & $0.76 \mathrm{~b}$ & $0.78 \mathrm{~b}$ & $0.74 \mathrm{a}, \mathrm{b}$ & $0.62 \mathrm{a}$ & $0.70 \mathrm{a}, \mathrm{b}$ & $0.64 \mathrm{a}, \mathrm{b}$ \\
\hline 19 & Dp-3-pcoumglc (cis) & $0.10 \mathrm{a}$ & $0.11 \mathrm{a}, \mathrm{b}$ & $0.10 \mathrm{a}$ & $0.18 \mathrm{c}$ & $0.20 \mathrm{c}$ & $0.16 \mathrm{~b}, \mathrm{c}$ \\
\hline 20 & Pn-3-acetylglc & $0.25 \mathrm{a}$ & $0.25 \mathrm{a}$ & $0.23 \mathrm{a}$ & $0.25 \mathrm{a}$ & $0.22 \mathrm{a}$ & $0.20 \mathrm{a}$ \\
\hline 21 & Mv-3-acetylglc & $1.87 \mathrm{~b}$ & $1.95 \mathrm{~b}$ & $1.78 \mathrm{~b}$ & $1.39 \mathrm{a}$ & $1.27 \mathrm{a}$ & $1.46 \mathrm{a}$ \\
\hline 22 & Dp-3-pcoumglc (trans) & $1.26 \mathrm{a}$ & $1.16 \mathrm{a}$ & $1.23 \mathrm{a}$ & $1.97 \mathrm{~b}$ & $1.99 \mathrm{~b}$ & $1.27 \mathrm{a}$ \\
\hline 23 & Pt-3-pcoumglc (cis) & $0.05 \mathrm{a}, \mathrm{b}$ & $0.04 \mathrm{a}$ & $0.04 \mathrm{a}$ & $0.09 \mathrm{c}$ & $0.09 \mathrm{c}$ & $0.07 \mathrm{~b}, \mathrm{c}$ \\
\hline 24 & Pn-3-cafglc & $0.07 \mathrm{a}, \mathrm{b}$ & $0.05 \mathrm{a}$ & $0.05 \mathrm{a}$ & $0.12 \mathrm{c}$ & $0.09 \mathrm{~b}$ & $0.07 \mathrm{a}, \mathrm{b}$ \\
\hline 25 & Mv-3-cafglc & $0.23 \mathrm{a}$ & $0.20 \mathrm{a}$ & $0.22 \mathrm{a}$ & $0.31 \mathrm{~b}$ & $0.25 \mathrm{a}$ & $0.24 \mathrm{a}$ \\
\hline 26 & Cy-3-pcumglc (trans) & 0.19 a & $0.16 \mathrm{a}$ & $0.17 \mathrm{a}$ & $0.30 \mathrm{~b}$ & $0.24 \mathrm{a}$ & $0.19 \mathrm{a}$ \\
\hline 27 & Pt-3-pcumglc (trans) & $0.81 \mathrm{a}$ & $0.78 \mathrm{a}$ & $0.81 \mathrm{a}$ & $1.26 \mathrm{~b}$ & $1.12 \mathrm{~b}$ & $0.90 \mathrm{a}$ \\
\hline 28 & Mv 3-pcoumglc (cis) & $0.23 \mathrm{a}$ & $0.21 \mathrm{a}$ & $0.19 \mathrm{a}$ & $0.29 \mathrm{a}$ & $0.23 \mathrm{a}$ & $0.19 \mathrm{a}$ \\
\hline 29 & Pn 3-pcoumglc (trans) & $0.45 \mathrm{a}$ & $0.42 \mathrm{a}$ & $0.44 \mathrm{a}$ & $0.77 \mathrm{c}$ & $0.66 \mathrm{~b}, \mathrm{c}$ & $0.50 \mathrm{a}, \mathrm{b}$ \\
\hline 30 & Mv 3-pcoumglc (trans) & $2.49 \mathrm{a}$ & $2.44 \mathrm{a}$ & $2.81 \mathrm{a}$ & $4.40 \mathrm{c}$ & $4.30 \mathrm{~b}, \mathrm{c}$ & $3.77 \mathrm{~b}$ \\
\hline 31 & Vit VF Mv-3-glc & $0.10 \mathrm{a}$ & $0.11 \mathrm{a}$ & $0.12 \mathrm{a}$ & $0.11 \mathrm{a}$ & $0.10 \mathrm{a}$ & $0.07 \mathrm{a}$ \\
\hline 32 & DRP & $17.08 \mathrm{a}$ & $17.13 \mathrm{a}$ & $17.18 \mathrm{a}$ & $21.77 \mathrm{a}$ & $24.98 \mathrm{a}$ & $17.32 \mathrm{a}$ \\
\hline
\end{tabular}

${ }^{a}$ Different letters in the same row indicate significant differences $(p<0.05) .{ }^{b} \mathrm{~F}-\mathrm{A}^{+}$, flavanol-anthocyanin direct condensation products; GC, gallocatechin; C, catechin; Dp, delphinidin; Cy, cyanidin; Pt, petunidin; Pn, peonidin; Mv, malvidin; glc, glucoside; pcoum, $p$-coumaroyl; caf, caffeoy; Vit A, A-type vitisin; Vit B, B-type vitisin; Vit VF, vinylphenol pyranoanthocyanin; DRP, difficult resolution pigments.

among samples, a principal component analysis (PCA) was performed from the percentages of the individual pigments over the total pigment content. The three first principal components (PC1, PC2, and PC3) explained $85 \%$ of the total system variability. Figure la shows the projection of the wine samples on the plane defined by the first and second principal components (PC2 vs PC1). In the PCA plot the samples treated with any of these products (T1 or M1) are well separated from control samples (C1) along the PC1 factor. In fact, control samples have a positive value, whereas the two others are negative. Taking into account the loadings (Figure $1 \mathrm{~b}$ and Table 2, for the identity of the variables), positive values are mainly correlated with grape native anthocyanins and negative values with $\mathrm{F}-\mathrm{A}^{+}$derivative pigments and with A-type vitisins. This means that these types of derivative pigments are more represented in the samples treated with enological tannin or with product $M$ than in control wines, whereas the weight of native anthocyanins is higher in control wines than in treated ones. In previous studies carried out in our laboratory not only in model solutions (data not shown) but also in wines, ${ }^{18}$ it has been observed that the synthesis of these types of derivative pigments is favored by the presence of the enological tannin.
With respect to the synthesis of A-type vitisins, it has been demonstrated that it requires the presence not only of anthocyanins and pyruvic acid but also of oxidants to complete the last step of the synthesis. ${ }^{35}$ Ellagitannins, which are present in the enological tannin employed in the present study, can promote the conversion of oxygen into reactive oxygen species which, in turn, might take part in the last step of the A-type vitisin synthesis. On the other hand, the enological tannin employed in this study also contained oligomeric proanthocyanidins having interflavanic linkages that can be cleaved at the $\mathrm{pH}$ of the wine, releasing carbocations which, in turn, can react with anthocyanins and originate $\mathrm{F}-\mathrm{A}^{+}$dimers. ${ }^{32}$ Furthermore, this condensation reaction may be favored by the ellagitannins present in the enological tannin. ${ }^{32,36}$

With regard to wines treated with product $M$, no evidence supporting the higher formation of anthocyanin-derived pigments was clearly found. In a recent work, Andújar-Ortiz and co-workers ${ }^{37}$ reported higher levels of vitisin B and of one isomer of malvidin 3-glucoside-ethyl-epicatechin in wines treated with glutathione-enriched inactive dry yeast (G-IDY) preparations than in control wines. Although no explanation is given, the higher contents of these two types of anthocyanin- 
Table 3. Percentages of Different Pigment Groups in Samples before Cold Treatment (C1, T1, and M1) and in Precipitates Obtained after Cold Treatment (C1p, T1p, and M1p) (Mean Values, $n=2$ )

\begin{tabular}{|c|c|c|c|c|c|c|}
\hline \multirow[b]{2}{*}{ pigment group $^{b}$} & \multicolumn{6}{|c|}{ samples ${ }^{a}$} \\
\hline & $\mathrm{C} 1$ & $\mathrm{~T} 1$ & M1 & C1p & $\mathrm{T} 1 \mathrm{p}$ & M1p \\
\hline F-A $A^{+}$ & $2.34 \mathrm{a}, \mathrm{b}$ & $2.40 \mathrm{a}, \mathrm{b}$ & $2.50 \mathrm{~b}$ & $1.15 \mathrm{a}$ & $1.43 \mathrm{a}, \mathrm{b}$ & $1.15 \mathrm{a}$ \\
\hline monoglucosides & 70.15 a & $70.21 \mathrm{a}$ & 69.75 a & $62.30 \mathrm{a}$ & 59.74 a & $69.63 \mathrm{a}$ \\
\hline acetylglucosides & $3.55 \mathrm{a}$ & $3.64 \mathrm{a}$ & $3.40 \mathrm{a}, \mathrm{b}$ & $2.85 \mathrm{~b}$ & $2.85 \mathrm{~b}$ & $2.91 \mathrm{~b}$ \\
\hline coumaroylglucosides & $5.58 \mathrm{a}$ & $5.32 \mathrm{a}$ & $5.78 \mathrm{a}$ & $9.26 \mathrm{c}$ & $8.83 \mathrm{~b}, \mathrm{c}$ & $7.06 \mathrm{a}, \mathrm{b}$ \\
\hline caffeoylglucosides & $0.30 \mathrm{a}, \mathrm{b}$ & $0.26 \mathrm{a}$ & $0.27 \mathrm{a}, \mathrm{b}$ & $0.43 \mathrm{c}$ & $0.35 \mathrm{~b}, \mathrm{c}$ & $0.31 \mathrm{a}, \mathrm{b}$ \\
\hline A-type vitisins & $0.83 \mathrm{a}$ & $0.83 \mathrm{a}$ & $0.93 \mathrm{a}, \mathrm{b}$ & $1.98 \mathrm{c}$ & $1.59 \mathrm{c}$ & $1.41 \mathrm{~b}, \mathrm{c}$ \\
\hline B-type vitisins & $0.08 \mathrm{a}$ & $0.10 \mathrm{a}$ & $0.08 \mathrm{a}$ & $0.15 \mathrm{a}$ & $0.15 \mathrm{a}$ & $0.15 \mathrm{a}$ \\
\hline Vit VF Mv-3-glc & $0.10 \mathrm{a}$ & $0.11 \mathrm{a}$ & $0.12 \mathrm{a}$ & $0.11 \mathrm{a}$ & $0.10 \mathrm{a}$ & $0.07 \mathrm{a}$ \\
\hline DRP & $17.08 \mathrm{a}$ & $17.13 \mathrm{a}$ & $17.18 \mathrm{a}$ & $21.77 \mathrm{a}$ & $24.98 \mathrm{a}$ & $17.32 \mathrm{a}$ \\
\hline
\end{tabular}

${ }^{a}$ Different letters in the same row indicate significant differences $(p<0.05) .{ }^{b} \mathrm{~F}-\mathrm{A}^{+}$, flavanol-anthocyanin direct condensation products; Mv, malvidin; glc, glucoside; Vit VF, vinylphenol pyranoanthocyanin; DRP, difficult elution compounds.

derived pigments might be related to a higher availability of acetaldehyde in the G-IDY wines, which can be, in turn, related to the glutathione content. Thus, in that study, the addition of the G-IDY preparations caused a chemical transformation of the grape native anthocyanins into derivative pigments in which formation acetaldehyde is involved. This was not the case in the present work, and the higher percentages of A-type vitisins and $\mathrm{F}-\mathrm{A}^{+}$derivative pigments in $\mathrm{M}$-treated samples may be related to a colloidal stabilization of the coloring matter. In fact, some polysaccharides are traditionally considered as "protective" colloids, macromolecular colloids that coat other colloids present in the wine, thus preventing their agglomeration. ${ }^{3}$ Riou and co-workers ${ }^{22}$ demonstrated the different ability of different wine polysaccharides to prevent the aggregation of tannin colloids. Among them and at their usual concentration in wines, only mannoproteins were able to prevent the growth of tannin particles and, therefore, their flocculation and precipitation. These authors proposed that this protective effect was due to the adsorption of the mannoprotein on the particles formed by tannins. Further studies carried out by the same research group $^{24}$ confirmed that the mechanism involved was steric stabilization and that the molecular weight of the polysaccharide conditioned the activity of the mannoprotein. Medium $(\sim 62 \mathrm{kDa})$ and low $(\sim 51 \mathrm{kDa})$ molecular weight polymers were more efficient than high molecular weight polymers $(\sim 337 \mathrm{kDa})$. Because $\mathrm{F}^{-\mathrm{A}^{+}}$dimers are originated from the direct condensation of a flavanol and an anthocyanin, a similar protective mechanism can be proposed for them. Product $\mathrm{M}$, containing medium and low molecular weight polymers, might have prevented the aggregation of $\mathrm{F}-\mathrm{A}^{+}$dimers or even the aggregation of these colored dimers with other proanthocyanidins that probably occurred in control samples.

The higher percentages of A-type vitisins found in M-treated samples might be also related to their colloidal stabilization. The additional pyran ring confers hydrophobicity to the molecules, making them less polar and less soluble in hydroalcoholic solutions (wine) than the original anthocyanins from which they are synthesized. Furthermore, unlike anthocyanins, the main species of which at wine $\mathrm{pH}$ is the colorless hemiketal form, the main species of the A-type vitisins is the orange quinonoidal base, ${ }^{38}$ which can also be responsible for the lower solubility of these anthocyanin derivatives. The lower solubility might favor interactions (hydrophobic and/or $\pi-\pi$ interactions) between molecules that might induce their aggregation and cause their precipitation. Mannoproteins might have acted as steric stabilizers, being adsorbed on the pigment and thus lowering the possibility of aggregation.

Although along PC1 the samples treated with product M (M1) and those treated with the enological tannin (T1) showed similar values, they were well separated along PC2. In general, the positive values of PC2 correlate with most of the F$\mathrm{A}^{+}$dimers and with all of the trans-isomers of the anthocyanin coumaroylglucosides, and the negative values correlate above all with acetylglucosides and with the cis-isomers of the coumaroylglucosides. M-treated samples showed positive values and tannin-treated samples showed negative values. In fact, although the percentages of coumaroyl derivatives were quite similar in both types of samples, the percentage represented by the cis-isomers was higher in the case of tannin-treated wines than in M-treated samples. This was also the case for acetyl derivatives, which represented higher percentages in the former than in the latter ones. On the contrary, the trans-isomers of the coumaroyl derivatives and the A-type vitisins were more represented in M-treated samples. Control wines showed percentages of cis-coumaroyl derivatives that were similar to those of tannin-treated wines and percentages of acetyl derivatives between those of treated wines. As a result, control wines showed a negative value of PC2.

Thus, the addition of either the enological tannin or product $\mathrm{M}$ to the wines causes some modifications in the pigment composition. The main composition differences between control and treated wines shown by PCA are the higher proportion of anthocyanin-derived pigments (A-type vitisins and $\mathrm{F}-\mathrm{A}^{+}$dimers, above all) in treated samples in relation to control wines and between treated wines, the different proportions of cis- and trans-isomers of the coumaroyl derivatives, the different percentages of acetyl derivatives, and the different proportions of A-type vitisins. The changes in the color parameters observed in the treated wines (M1 and T1) in relation to control (C1) wine can be, therefore, explained by these changes in the composition. The decrease in lightness might be due to the higher pigment content observed in both types of treated samples in relation to control ones. In the case of tannin-treated wines, the decrease in $L^{*}$ might be also due to other phenolic compounds supplied by the enological tannin such as proanthocyanidins. In the case of M-treated wines, $L^{*}$ might partly decrease as a consequence of the polysaccharidic nature of the enological product tested. The increase in the hue observed in the treated samples in relation to control wines might be due to the increase in the percentage of the derivative 
pigments that are redder or more orange (above all, A-type vitisins and $\mathrm{F}-\mathrm{A}^{+}$dimers) at wine $\mathrm{pH}$.

Modification of the Pigment Composition after Cold Treatment. Figure 1a also shows the location of the samples along $\mathrm{PC} 1$ and $\mathrm{PC} 2$ after cold treatment $(\mathrm{C} 1 *, \mathrm{~T} 1 *$, and $\mathrm{M} 1 *)$. Cold treatment barely modified PC1 in control and M-treated wines, whereas it caused a decrease in PC1 in the samples to which enological tannin was added. This decrease correlates with an increase in the percentage represented by some anthocyanin derivatives ( $\mathrm{F}-\mathrm{A}^{+}$dimers and A-type vitisins) and with a decrease in the percentage of native grape anthocyanins. On the contrary, all types of samples increased the values of PC2 in relation to those of the samples not subjected to cold treatment. Taking into account the loadings of this PCA (Figure $1 \mathrm{~b}$ ), an increase in PC2 correlates with a decrease in acetyl and cis-coumaroyl derivatives and with an increase of the percentages of F-A $\mathrm{A}^{+}$dimers, trans-coumaroyl derivatives, and some A-type vitisins. It has to be noted that M-treated samples showed the lowest change along PC2 after cold treatment. Thus, taking into account that these samples barely changed along PC1, the addition of product $\mathrm{M}$ to the samples seems to stabilize the pigment composition against cold treatment. To determine the compound groups that are mostly benefited by these enological practices, the percentages of the main pigments in the sample before cold treatment were compared to those determined in the precipitates (see Table 2 for the percentages of the individual compounds and Table 3 for the percentages of the main groups of pigments). It was first observed that in all types of wine the total percentage of the F$\mathrm{A}^{+}$dimers was lower in the precipitates than in the sample not subjected to cold treatment. This means that independent of the addition of one or other enological product $\mathrm{F}-\mathrm{A}^{+}$dimers are quite unaffected by cold treatment. In fact, some of these dimers that were present in the samples not subjected to cold treatment were not detected in the precipitates (Table 2). Although for most of the F-A $\mathrm{A}^{+}$dimers the lowest percentages were found in the precipitates of the M-treated samples, differences among treatments were not significant. On the contrary, the difficult resolution pigments responsible for the hump observed at the last part of the chromatogram were more represented in the precipitates than in the samples before being cooled. This is indicative of certain instability of this type of pigment against cold treatment. The lowest increase in the percentages was found in $\mathrm{M}$-treated wines, pointing to a stabilizing effect of this product in this type of compound. Although the exact nature of these difficult resolution pigments is not well established, they are supposed to be polymeric pigments, and, in fact, dimeric anthocyanins have been reported to be a part of this group of pigments. ${ }^{33}$ Product $M$ probably caused their colloidal stabilization. The enological tannin employed in this study, on the contrary, caused a higher precipitation of these compounds, which is probably related to the higher content (data not shown) detected in this type of sample. However, from a statistical point of view, the percentages of this group of compounds in the precipitates were not statistically different in the different wines. In all of the samples, the percentage of anthocyanin monoglucosides decreased in the precipitates in relation to the samples before cold treatment. However, M-treated samples were those for which the percentages changed less. With respect to acyl derivatives, it was observed that, in general, the percentages of the acetylglucosides were lower in the precipitates than in the samples not subjected to cold treatment, whereas coumaroyl and caffeoyl glucosides increased their percentages in the precipitates (Tables 2 and 3). This is indicative of a higher instability of coumaroyl and caffeoyl glucosides toward cold in relation to acetyl derivatives. However, differences were observed among treatments. In the case of the coumaroylglucosides, the percentages found in the precipitates of control and tannin-treated samples were statistically higher than those determined in the samples not subjected to cold treatment. In the case of the samples treated with product $M$, the percentages of most of the coumaroylglucosides were not statistically different from those determined in the sample before cold treatment (Table 2). This fact points to a protective effect of product $\mathrm{M}$ toward the precipitation of this group of compounds caused by cold treatment. Gonçalves and co-workers ${ }^{39}$ reported higher retention of malvidin 3-O-p-coumaroylglucoside by wine polymeric material in relation to other acetylated and nonacylated anthocyanins, which was attributed to the higher hydrophobicity of the coumaroylglucosides, which can increase the hydrophobic interactions between them and the polymeric material. The studies of Morata and co-workers ${ }^{40,41}$ on the adsorption of anthocyanins on yeast cell walls also demonstrated that coumaroyl derivatives were the most adsorbed compounds, even in different yeast strains. Taking into account that the structure of the mannoproteins present in the cell wall of $S$. cerevisiae is similar to that of the mannoproteins released by the yeast to the wines and that they can represent up to $50 \%$ of the cell wall ${ }^{20}$ and $80 \%$ of the exocellular polysaccharides released by yeast to the wines, ${ }^{3}$ it can be assumed that coumaroyl derivatives are more retained by product $M$ than other anthocyanins, thus being protected from precipitation by cold treatment. In the case of caffeoyl derivatives, the increase of the percentage in the precipitate was significant only in control samples, thus indicating differences between control samples and tannin- or M-treated samples. The percentage of the A-type vitisins also increased in the precipitates of all types of samples, but again, M-treated samples were those that changed less (Tables 2 and 3). Cold treatment reduces the solubility of the pigments and, as previously indicated, the solubility of A-type vitisins seems to be lower than that of the anthocyanins from which they are synthesized. For this reason, A-type vitisins were more affected by cold treatment than anthocyanins and their percentages increased in the precipitates in relation to those found in non-cold-treated samples. Cold might have favored the hydrophobic interactions between molecules and caused their precipitation. The addition of product $\mathrm{M}$ might have reduced this precipitation by adsorption of the mannoprotein on the pigment molecule, hindering the hydrophobic interactions. The malvidin 3-O-glucoside vinylphenol pyranoanthocyanin seemed to be quite stable against cold treatment because its percentage in the precipitates was similar to that detected in the samples before cold treatment (Tables 2 and 3). Although differences between treatments were not significant, the precipitates from M-treated samples were those that showed the lowest percentages in relation to the initial percentages, which might be indicative of the possible protective effect of product $M$ against the precipitation of this pyranoanthocyanin by cold. Thus, it can be seen that the most relevant changes in the percentages of the pigments between control samples and their precipitates (decrease of anthocyanin monoglucosides and their acetyl derivatives, increase of A-type vitisins and coumaroyl derivatives) were lowered with the use of product $M$. The addition of the enological tannin also 

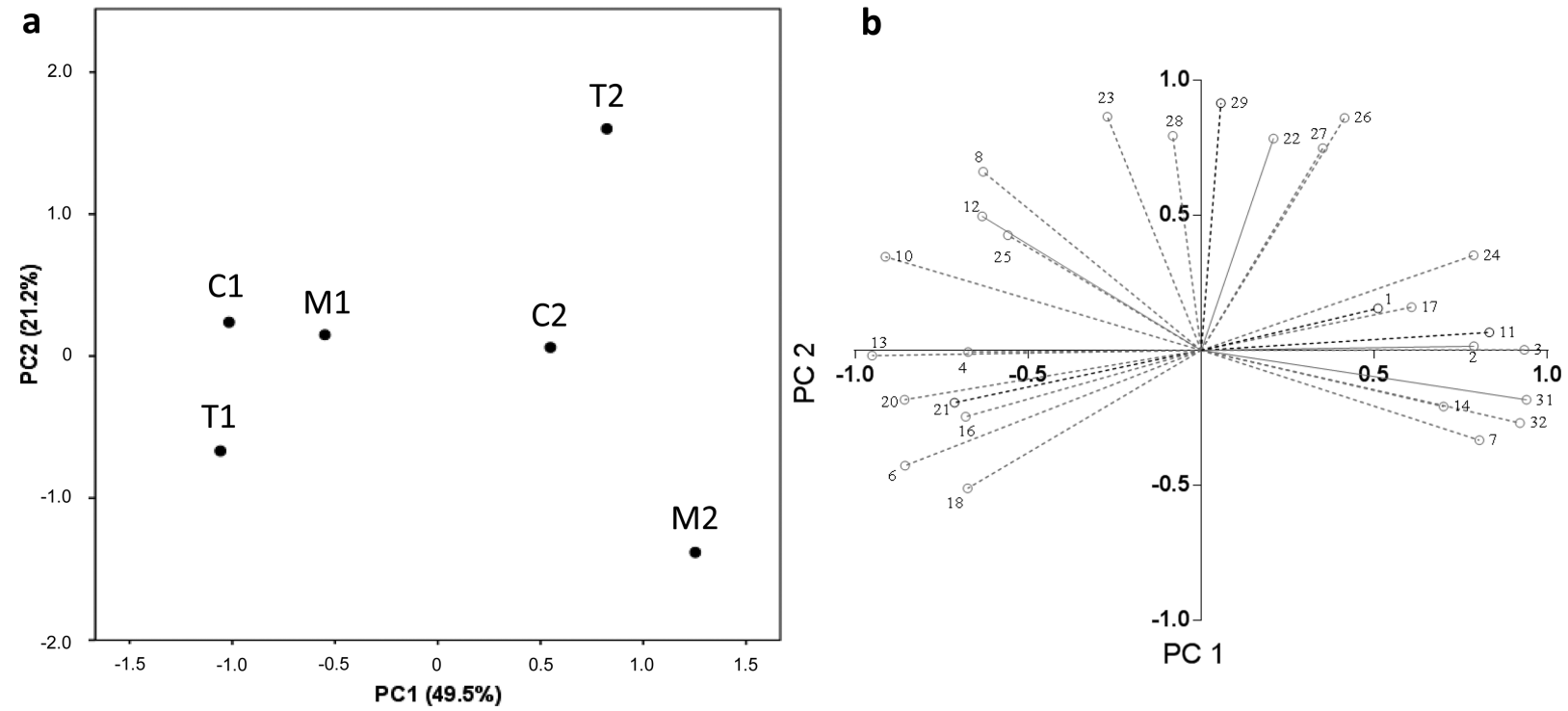

Figure 2. (a) Projection of the wine samples on the plane defined by the first and second principal components (PC2 vs PC1). These samples correspond to all wines (control, tannin- and M-treated wines) not subjected to cold in the first (samples C1, T1, or M1) and second sampling points (samples C2, T2, or M2). (b) Loadings of the original variables. The identities of the original variables are indicated in Table 2.
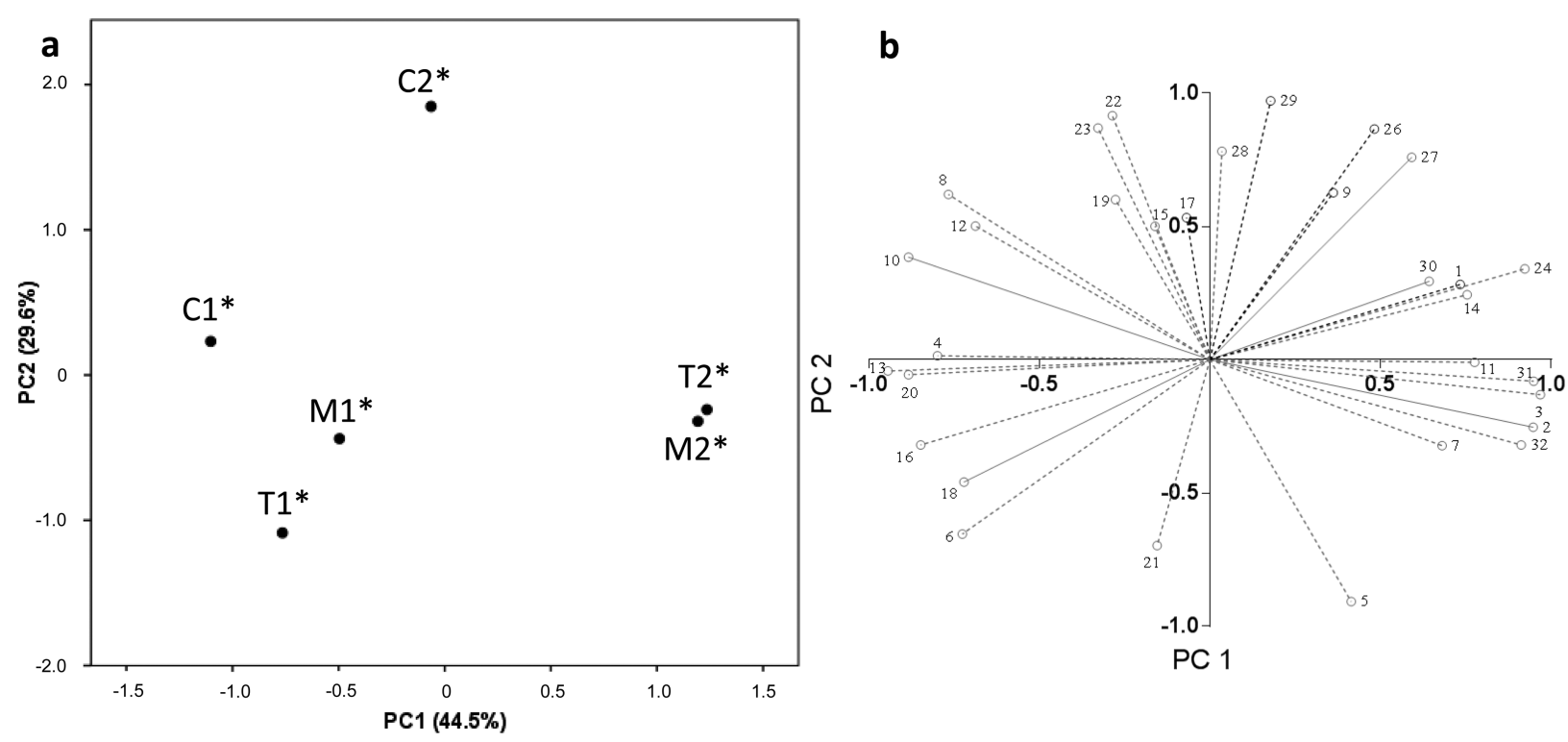

Figure 3. (a) Projection of the wine samples on the plane defined by the first and second principal components (PC2 vs PC1). These samples correspond to all wines (control, tannin- and M-treated wines) subjected to cold in the first (samples $\mathrm{C} 1^{*}, \mathrm{~T} 1^{*}$, or $\mathrm{M} 1^{*}$ ) and second sampling points (samples $\mathrm{C} 2 *, \mathrm{~T} 2 *$, or $\mathrm{M} 2 *$ ). (b) Loadings of the original variables. The identities of the original variables are indicated in Table 2 .

preserved the samples from some of these changes, but the effect was lower than in M-treated samples.

Modification of the Pigment Composition over Time. Figures 2 and 3 show the score plots for the samples not subjected to cold treatment in both sampling points (C1, T1, M1, C2, T2, and M2, Figure 2) and for the samples subjected to cold treatment $\left(\mathrm{C} 1^{*}, \mathrm{~T} 1 *, \mathrm{M} 1 *, \mathrm{C} 2 *, \mathrm{~T} 2 *\right.$, and $\mathrm{M} 2 *$, Figure 3 ). In both cases it can be seen that all of the samples are separated along PC1 according to sampling point, with the younger samples showing negative scores and the older ones, positive. According to the loadings (Figure $2 b$ and $3 b$ ), this change from negative to positive scores with age is related to a decrease in anthocyanin monoglucosides, acetylglucosides, and B-type vitisin and to an increase in derivative pigments $\left(\mathrm{F}-\mathrm{A}^{+}\right.$ dimers, A-type vitisins, malvidin 3-O-glucoside vinylphenol pyranoanthocyanin, and difficult resolution pigments). This is in accordance with what might be expected because as wine ages native anthocyanins react with other wine constituents, giving rise to anthocyanin-derived pigments. Nevertheless, some differences could be observed among treatments in both sample series (subjected and not subjected to cold treatment). In general, in sampling point 2 , control samples were those that showed the lowest positive values of PC1. Tannin- or M-treated samples, on the contrary, showed the highest positive values. This means that independent of being cold-treated or not, tannin and M-treated wines still show higher percentages of derivative pigments than control wines after 10 weeks. In the series of wines not subjected to cold treatment (C2, T2, and M2), tannin- and M-treated samples were further separated along PC2, mainly due to higher percentages of derivative 
pigments in M-treated samples and higher percentages of anthocyanin coumaroylglucosides in tannin-treated samples. However, these changes in the composition hardly cause differences in the CIELAB parameters because differences between $\mathrm{T} 2$ and $\mathrm{M} 2$ were not significant (Table 1 ). In the series of samples subjected to cold treatment $(\mathrm{C} 2 *, \mathrm{~T} 2 *$, and $\mathrm{M} 2 *)$, there were no differences along PC2 between $\mathrm{T} 2 *$ and $\mathrm{M} 2 *$. However, important differences along PC1 and PC2 could be observed between $\mathrm{C} 2 *$ and the treated samples $(\mathrm{T} 2 *$ and $\mathrm{M} 2 *$ ) that were higher than in the case of the samples not subjected to cold. $\mathrm{C} 2 *$ shows a $\mathrm{PC} 1$ value next to zero and a PC2 positive value distant from the $\mathrm{PC} 2$ value of treated samples. This is related in both coordinates to lower percentages of derivative pigments. It has to be borne in mind that $\mathrm{C}_{2} *$ samples come from $\mathrm{C1}^{*}$, control samples subjected to cold, that had already lost a part of the anthocyanin derivatives due to cold treatment. For this reason, differences between control and treated wines were higher in the cold-treated series than in the non-cold-treated ones. As previously indicated, $\mathrm{C} 2 *$ samples showed significantly higher values of lightness and lower values of chroma than treated wines $\left(\mathrm{T}_{2}^{*}\right.$ and $\left.\mathrm{M} 2 *\right)$. This means that even after 10 weeks from cold treatment, wines treated either with the enological tannin or with product $M$ still show higher percentages of derivative pigments in relation to control wines.

In conclusion, the usefulness of the addition of either an enological tannin containing condensed and hydrolyzable tannins or a mannoprotein with medium-low molecular weight (product $\mathrm{M}$ ) in stabilizing wine color against cold treatment has been demonstrated. Both enological treatments have been proven to slightly increase the hue of the wines to which they are added and to better maintain the color $\left(L^{*}\right.$, $\left.C_{a b} * h_{a b}\right)$ of those samples after cold treatment than control samples. Furthermore, although time affected similarly all types of samples, after 10 weeks from malolactic fermentation (sampling point 2) tannin- and M-treated samples, either subjected to cold or not, still showed CIELAB color parameters more similar to those shown by control wines before cold treatment than those shown by control wines at sampling point 2. The pigment analysis has revealed that both enological treatments increased the percentages of anthocyanin-derived pigments in relation to control wines not only in wines not subjected to cold treatment but above all in cold-treated wines. In the case of the enological tannin, the higher percentages observed for these derivatives is probably due to a higher synthesis because the addition of the enological tannin can favor the extraction of anthocyanins from grapes during the maceration/alcoholic fermentation step and supplies substrates and/or oxidants to complete the synthesis reactions. Thus, the addition of the enological tannin leads to a chemical stabilization of the coloring matter of the wines, because grape native anthocyanins are transformed into anthocyaninderived pigments that are chemically more resistant than anthocyanins toward hydration and/or $\mathrm{SO}_{2}$ bleaching. In the case of the mannoprotein, it seems that the stabilization of the coloring matter consists of a colloidal stabilization. Cold treatment forced the precipitation of unstable coloring matter, revealing the unexpected colloidal instability of some chemically stable anthocyanin-derived pigments, such as A-type vitisins. However, the mannoprotein employed in the present study has been able to reduce the cold-induced precipitation of A-type vitisins and other derivative pigments and the spontaneous precipitation of these compounds in non-cold- treated samples. To our knowledge, this is the first report on the stabilizing effect of mannoproteins on anthocyanin derivative pigments. Further studies aim at evaluating the effect of the addition of both enological products to the same wine to attain a chemical and colloidal stability of the coloring matter.

\section{AUTHOR INFORMATION}

\section{Corresponding Author}

*(M.T.E.-B.) Phone: +34 923 294537. Fax: +34 923 294515. Email: escriban@usal.es.

\section{Funding}

Thanks are due to the Spanish MICINN (Project ref AGL2011-30254-C02-01) and to Project DEMETER program CENIT for financial support. I.G.-E. thanks the Spanish Ministerio de Educación for the F.P.U. predoctoral scholarship.

Notes

The authors declare no competing financial interest.

\section{ACKNOWLEDGMENTS}

We thank R. Boube for the preliminary studies from which the mannoprotein employed in the present study (product $M$ ) was selected.

\section{REFERENCES}

(1) Morrot, G.; Brochet, F.; Dubourdieu, D. The color of odors. Brain Language 2001, 79, 309-320.

(2) Österbauer, R. A.; Matthews, P. M.; Jenkinson, M.; Beckmann, C. F.; Hansen, P. C.; Calvert, G. A. Color of scents: chromatic stimuli modulate odor responses in the human brain. J. Neurophysiol. 2005, 93, 3434-3441.

(3) Ribéreau-Gayon, P.; Glories, Y.; Maujean, A.; Dubourdieu, D. Handbook of Enology. Vol. 2. The Chemistry of Wine Stabilization and Treatments, 2nd ed.; Wiley: Chichester, UK, 2003; 404 pp.

(4) Rentzsch, M.; Schwarz, M.; Winterhalter, P. Pyranoanthocyanins - an overview on structures, occurrence, and pathways of formation. Trends Food Sci. Technol. 2007, 18, 526-534.

(5) Sarni-Manchado, P.; Fulcrand, H.; Souquet, J.-M.; Cheynier, V.; Moutounet, M. Stability and color of unreported wine anthocyaninderived pigments. J. Food Sci. 1996, 61, 938-941.

(6) Bakker, J.; Timberlake, C. F. Isolation, identification, and characterization of new color-stable anthocyanins occurring in some red wines. J. Agric. Food Chem. 1997, 45, 35-43.

(7) Asenstorfer, R. E.; Lee, D. F.; Jones, G. P. Influence of structure on the ionization constants of anthocyanin and anthocyanin-like wine pigments. Anal. Chim. Acta 2006, 563, 10-14.

(8) Quijada-Morín, N.; Dangles, O.; Rivas-Gonzalo, J. C.; EscribanoBailón, M. T. Physico-chemical and chromatic characterization of malvidin 3-glucoside-vinylcatechol and malvidin 3-glucoside-vinylguaiacol wine pigments. J. Agric. Food Chem. 2010, 58, 9744-9752.

(9) Dueñas, M.; Salas, E.; Cheynier, V.; Dangles, O.; Fulcrand, H. UV-visible spectroscopic investigation of the 8,8-methylmethine catechin-malvidin 3-glucoside pigments in aqueous solution: structural transformations and molecular complexation with chlorogenic acid. $J$. Agric. Food Chem. 2006, 54, 189-196.

(10) Escribano-Bailón, M. T.; Álvarez-García, M.; Rivas-Gonzalo, J. C.; Heredia, F. J.; Santos-Buelga, C. Color and stability of pigments derived from the acetaldehyde-mediated condensation between malvidin 3-O-glucoside and (+)-catechin. J. Agric. Food Chem. 2001, 49, 1213-1217.

(11) Salas, E.; Le Guernevé, C.; Fulcrand, H.; Poncet-Legrand, C.; Cheynier, V. Structure determination and colour properties of a new directly linked flavanol-anthocyanin dimer. Tetrahedron Lett. 2004, 45, $8725-8729$.

(12) Darias-Martín, J.; Carrillo, M.; Díaz, E.; Boulton, R. B. Enhancement of red wine colour by pre-fermentation addition of copigments. Food Chem. 2001, 73, 217-220. 
(13) González-Manzano, S.; Dueñas, M.; Rivas-Gonzalo, J. C.; Escribano-Bailón, M. T.; Santos-Buelga, C. Studies on the copigmentation between anthocyanins and flavan-3-ols and their influence in the colour expression of red wine. Food Chem. 2009, 114, 649-656.

(14) Harbertson, J. F.; Parpinello, G. P.; Heymann, H.; Downey, M. $\mathrm{O}$. Impact of exogenous tannin additions on wine chemistry and wine sensory character. Food Chem. 2012, 131, 999-1008.

(15) Bautista-Ortín, A. B.; Fernández-Fernández, J. I.; López-Roca, J. M.; Gómez-Plaza, E. The effects of enological practices in anthocyanins, phenolic compounds and wine colour and their dependence on grape characteristics. J. Food Compos. Anal. 2007, 20, 546-552.

(16) Parker, M.; Smith, P. A.; Birse, M.; Francis, I. L.; Kwiatkowski, M. J.; Lattey, K. A.; Liebich, B.; Herderich, M. J. The effect of pre- and post-ferment additions of grape derived tannin on Shiraz wine sensory properties and phenolic composition. Aust. J. Grape Wine Res. 2007, $13,30-37$.

(17) Pérez-Lamela, C.; García-Falcón, M. S.; Simal-Gándara, J.; Orriols-Fernández, I. Influence of grape variety, vine system and enological treatments on the colour stability of young red wines. Food Chem. 2007, 101, 601-606.

(18) Alcalde-Eon, C.; García-Estévez, I.; Ferreras-Charro, R.; RivasGonzalo, J. C.; Ferrer-Gallego, R.; Escribano-Bailón, M. T. Adding oenological tannin vs. overripe grapes: effect on the phenolic composition of red wines. J. Food Compos. Anal. 2014, DOI: $10.1016 /$ j.jfca.2014.01.004.

(19) Dupin, I. V. S.; Stockdale, V. J.; Williams, P. J.; Jones, G. P.; Markides, A. J.; Waters, E. J. Saccharomyces cerevisiae mannoproteins that protect wine from protein haze: evaluation of extraction methods and immunolocalization. J. Agric. Food Chem. 2000, 48, 1086-1095.

(20) Ribéreau-Gayon, P.; Dubourdieu, D.; Donèche, B.; Lonvaud, A. Handbook of Enology. Vol. 1. The Microbiology of Wine and Vinifications, 1st ed.; Wiley: Chichester, UK, 2000; 454 pp.

(21) Pellerin, P.; Cabanis, J. C. Los glúcidos. In Enología: Fundamentos Cientificos y Tecnológicos, 2nd ed.; Flanzy, C., Ed.; AMV Ediciones, Ediciones Mundi-Prensa: Madrid, Spain, 2003; 797 pp.

(22) Riou, V.; Vernhet, A.; Doco, T.; Moutounet, M. Aggregation of grape seed tannins in model wine-effect of wine polysaccharides. Food Hydrocolloids 2002, 16, 17-23.

(23) Rodrigues, A.; Ricardo-Da-Silva, J. M.; Lucas, C.; Laureano, O. Effect of commercial mannoproteins on wine colour and tannins stability. Food Chem. 2012, 131, 907-914.

(24) Poncet-Legrand, C.; Doco, T.; Williams, P.; Vernhet, A. Inhibition of grape seed tannin aggregation by wine mannoproteins: effect of polysaccharide molecular weight. Am. J. Enol. Vitic. 2007, 58, 87-91.

(25) Pozo-Bayón, M. A.; Andújar-Ortiz, M.; Moreno-Arribas, M. V. Scientific evidences beyond the application of inactive dry yeast preparations in winemaking. Food Res. Int. 2009, 42, 754-761.

(26) Escot, S.; Feuillat, M.; Dulau, L.; Charpentier, C. Release of polysaccharides by yeasts and the influence of released polysaccharides on colour stability and wine astringency. Aust. J. Grape Wine Res. 2001, $7,153-159$.

(27) Guadalupe, Z.; Martínez, L.; Ayestarán, B. Yeast mannoproteins in red winemaking: effect on polysaccharide, polyphenolic, and color composition. Am. J. Enol. Vitic. 2010, 61, 191-200.

(28) Guadalupe, Z.; Ayestarán, B. Effect of commercial mannoprotein addition on polysaccharide, polyphenolic, and color composition in red wines. J. Agric. Food Chem. 2008, 5, 9022-9029.

(29) Fernández, O.; Martínez, O.; Hernández, Z.; Guadalupe, Z.; Ayestarán, B. Effect of the presence of lysated lees on polysaccharides, color and main phenolic compounds of red wine during barrel ageing. Food Res. Int. 2011, 44, 84-91.

(30) Ferrer-Gallego, R.; García-Marino, M.; Hernández-Hierro, J. M.; Rivas-Gonzalo, J. C.; Escribano-Bailón, M. T. Statistical correlation between flavanolic composition, colour and sensorial parameters in grape seed during ripening. Anal. Chim. Acta 2010, 660, 22-28.
(31) Heredia, F. J.; Álvarez, C.; González-Miret, M. L.; Ramírez, A. CromaLab Análisis de Color; Registro General de la Propiedad Intelectual: Sevilla, Spain, 2004; SE-1052-04.

(32) Alcalde-Eon, C.; Escribano-Bailón, M. T.; Santos-Buelga, C.; Rivas-Gonzalo, J. C. Changes in the detailed pigment composition of red wine during maturity and ageing. A comprehensive study. Anal. Chim. Acta 2006, 563, 238-254.

(33) Alcalde-Eon, C.; Escribano-Bailón, M. T.; Santos-Buelga, C.; Rivas-Gonzalo, J. C. Identification of dimeric anthocyanins and new oligomeric pigments in red wine by means of HPLC-DAD-ESI/MS ${ }^{n}$. J. Mass Spectrom. 2007, 42, 735-748.

(34) Martínez, J. A.; Melgosa, M.; Pérez, M. M.; Hita, E.; Negueruela, A. I. Visual and instrumental color evaluation in red wines. Food Sci. Technol. Int. 2001, 7, 439-444.

(35) Asenstorfer, R. E.; Markides, A. J.; Iland, P. G.; Jones, G. Formation of vitisin A during red wine fermentation and maturation. Aust. J. Grape Wine Res. 2003, 9, 40-46.

(36) Vivas, N.; Glories, Y. Role of oak wood ellagitannins in the oxidation process of red wines during aging. Am. J. Enol. Vitic. 1996, 47, 103-107.

(37) Andújar-Ortiz, I.; Pozo-Bayón, M. A.; Garrido, I.; MartínÁlvarez, P. J.; Bartolomé, B.; Moreno-Arribas, M. V. Effect of using glutathione-enriched inactive dry yeast preparations on the phenolic composition of rosé Grenache wines during winemaking. J. Int. Sci. Vigne Vin 2012, 46, 241-251.

(38) Asenstorfer, R. E.; Jones, G. P. Charge equilibria and $\mathrm{pK}$ values of 5-carboxypyranomalvidin-3-glucoside (vitisin A) by electrophoresis and absorption spectroscopy. Tetrahedron 2007, 63, 4788-4792.

(39) Gonçalves, F. J.; Rocha, S. M.; Coimbra, A. Study of the retention capacity of anthocyanins by wine polymeric material. Food Chem. 2012, 134, 957-963.

(40) Morata, A.; Gómez-Cordovés, M. C.; Suberviola, J.; Bartolomé, B.; Colomo, B.; Suárez, J. A. Adsorption of anthocyanins by yeast cell walls during the fermentation of red wines. J. Agric. Food Chem. 2003, 51, 4084-4088.

(41) Morata, A.; Gómez-Cordovés, M. C.; Colomo, B.; Suárez, J. A. Cell wall anthocyanin adsorption by different Saccharomyces strains during the fermentation of Vitis vinifera L. cv Graciano grapes. Eur. Food Res. Technol. 2005, 220, 341-346. 